\title{
Pregnancy Outcomes and Associated Factors for Uterine Rupture: An 8 Years Population-based Retrospective Study
}

\section{Sheng Wan}

Shanghai First Maternity and Infant Hospital, Shanghai Tongji University School of Medicine

\section{Mengnan Yang}

Shanghai First Maternity and Infant Hospital, Shanghai Tongji University School of Medicine Jindan Pei

Shanghai First Maternity and Infant Hospital, Shanghai Tongji University School of Medicine

\section{Xiaobo Zhao}

Shanghai First Maternity and Infant Hospital, Shanghai Tongji University School of Medicine

\section{Chenchen Zhou}

Shanghai First Maternity and Infant Hospital, Shanghai Tongji University School of Medicine

\section{Yuelin Wu}

Shanghai First Maternity and Infant Hospital, Shanghai Tongji University School of Medicine

\section{Qianqian Sun}

Shanghai First Maternity and Infant Hospital, Shanghai Tongji University School of Medicine

\section{Guizhu Wu}

Shanghai First Maternity and Infant Hospital, Shanghai Tongji University School of Medicine

Xiaolin Hua ( $\nabla$ xiaolin_hua@tongji.edu.cn )

Shanghai First Maternity and Infant Hospital, Shanghai Tongji University School of Medicine

\section{Research Article}

Keywords: Uterine rupture, cesarean section, VBAC, maternal and neonatal outcome, risk factors

Posted Date: June 1st, 2021

DOl: https://doi.org/10.21203/rs.3.rs-558866/v1

License: (c) (i) This work is licensed under a Creative Commons Attribution 4.0 International License. Read Full License

Version of Record: A version of this preprint was published at BMC Pregnancy and Childbirth on February 1st, 2022. See the published version at https://doi.org/10.1186/s12884-022-04415-6. 


\section{Abstract}

Background: Uterine rupture is an obstetrical emergency with serious undesired complications for laboring mothers resulting in fatal maternal and neonatal outcomes. The aim of this study was to assess the incidence of uterine rupture, its association with previous uterine surgery and vaginal birth after caesarean section (VBAC), and the maternal and perinatal implications.

Methods: This is a population-based retrospective study. All pregnant women treated for ruptured uterus in one center between 2013 and 2020 were included. Their information retrieved from the medical records department were retrospectively reviewed.

Results: A total of 209,112 deliveries were included and 41 cases of uterine rupture were identified. The incidence of uterine rupture was 1.96/10 000 births. 16 (39.0\%) had maternal and fetal complications. There were no maternal deaths secondary to uterine rupture, while perinatal fatality related to uterine rupture was $7.3 \%$. Among all case, $38(92.7 \%)$ were scarred uterus and $3(7.3 \%)$ were unscarred uterus. The most common cause of uterine rupture was previous cesarean section, while cases with a history of laparoscopic myomectomy were more likely to have serious adverse outcome. 24 (59\%) of the ruptures occurred in anterior lower uterine segment. Fetal heart rate monitoring changes were the most reliable signs for rupture.

Conclusions: Incidence of uterine rupture in the study area was consistent with developed countries. Further improvement in obstetric care and strong collaboration with referring health facilities was needed to ensure maternal and perinatal safety.

\section{Background}

Uterine rupture (UR) is a full-thickness separation of the uterine wall through breaching during pregnancy, labor or immediately after delivery[1-3]. According to the world health organization, the average incidence of UR is 5.3 / I0000[1]. UR is one of the most dangerous obstetric problems and a lifethreatening emergency. It is an important cause of maternal and perinatal morbidity and mortality[4-6]. Maternal mortality ranges between $1 \%$ and $13 \%$ and neonatal mortality between $74 \%$ and $92 \%[1]$. The determinant factors for maternal and fetal outcomes of UR differ across geographical boundaries due to different socio-demographic status, the availability and accessibility of routine obstetric care and health system effectiveness. Analyzing outcomes and factors associated with maternal and fetal complications of UR in the study area is important to prevent and improve clinical management by designing policies and strategies.

Although the occurrence of UR is relatively rare, it is more frequent in low-income compared to highincome countries[7, 8]. In high-income countries, the greatest risk factor is a scarred uterus, typically from a previous cesarean delivery. Risks for UR are also related to factors such as parity, obstructed labor, induction of labor, use of prostaglandins, and/or breech presentation[1, 7, 9]. VBAC(vaginal birth after caesarean section) is an important option to reduce caesarean section rate. But in China, many hospitals 
are reluctant to attempt a TOLAC (trial of labour after caesarean delivery) for increasing the risks of severe adverse outcomes, such as UR and fetal or neonatal death. However, reports on UR and its maternal and perinatal outcomes for such delivery are lacking in China. As to scarred uterus, previous studies have generally concentrated on the outcome of UR mostly in patients with previous cesarean section, and few have described the outcome in patients with other gynecological surgery history.

The aim of this study was to analyze all cases of UR in our hospital during the period 2013-2020 to assess the incidence, the associations with previous caesarean, other gynecological surgery history, and the maternal and perinatal implications of UR.

\section{Methods}

\section{Study design and participants}

A retrospective analysis of UR cases was conducted at Shanghai First Maternity and Infant Hospital, Tongji University School of Medicine, from June 1, 2013 to December 31, 2020. This hospital is a tertiary referral center for critical and severe diseases of pregnant and delivery women and has the largest number of deliveries in East China region. This study was approved by the Ethics Review Committee of Shanghai First Maternity and Infant Hospital, Tongji University School of Medicine (KS20268).

We excluded cases with: pregnancies before 20 weeks, uterine dehiscence, traumatic of motor vehicle accidents.

\section{Variables of the study}

Patients with UR were divided in two groups according to maternal and/or fetal complications or not, and compared. Maternal complication was defined by estimated postpartum hemorrhage (blood loss volume more than $500 \mathrm{ml}$ after vaginal birth or more than $1000 \mathrm{ml}$ after caesarean section), hysterectomy, obstetric injury (genital and/or urinary injury) and maternal death. Neonatal complication was defined as Apgar score $<7$ at 5 min, neonatal intensive-care unit (NICU) admission, and neonatal death[10, 11]. A complete UR was defined as tearing in all layers of the uterine wall, including the serosa and amniotic membranes. An incomplete UR was defined as tearing in the muscular layers, with intact serosa or amniotic membranes[12].

We retrieved the charts of UR cases and collected independent variables : 1) socio-demographic characteristics (age, parity, education and place of residence; 2 ) pregnancy and labor related variables (previous cesarean section, ectopic pregnancy, uterine myomectomy and other uterine operation history, intrauterine operation; 3) clinical symptoms and signs 4) maternal and fetal outcomes (delivery method, blood loss and transfusion, postpartum hemorrhage, ICU, birth weight, 5-minute Apgar score < 7).

\section{Data processing and analysis}


All collected data were rechecked for completeness and coded. Then the data were entered and cleaned using Epidata 3.1 software. Data are expressed as mean \pm standard deviation, or median (25th-75th percentile). The normality of variables was assessed. Differences between two groups were compared with the Student's t-test and the Mann-Whitney U test for continuous variables: mean and median, respectively, and with the $\chi 2$ test or Fisher's exact test for categorical variables. We used the Spearman coefficient to assess the correlation between UR rate and VBAC rate. Multivariable logistic regression analysis was performed to examine the association of included variables with UR. Odds ratios (OR) were presented with $95 \%$ confidence intervals $(\mathrm{Cl})$. Statistical analyses were performed using SPSS software, version 22.0 (SPSS Inc., Chicago, IL, USA). A $p$ value of less than 0.05 was considered statistically significant.

\section{Results}

During the study period, 41 UR were identified among a total of 209,112 deliveries. The incidence of UR was 1.96/10 000 births. There were no maternal deaths, hysterectomy, and obstetric injury secondary to UR in our study. Among all cases, there were $16(39.0 \%)$ cases with complication and $25(61.0 \%)$ cases without. 15 (36.6\%) were complete rupture cases, and 26 (63.4\%) incomplete rupture cases. 38(92.7\%) were scarred uterus and $3(7.3 \%)$ were unscarred uterus.

The total number of deliveries and the rates scarred uterus and VBAC increased over the eight years. However, the proportion of UR remained consistent (Figure. 1). UR rate was not associated with VBAC rate (correlation coefficient: $-0.095, p=0.826$ ).

Demographic data and clinical characteristics of mothers and fetuses between UR and non-UR were presented in Table 1. Patients in UR group were significantly older and more than half (58.5\%) of them were over 35 years old, compared with $18.8 \%$ of the non-UR group. The mean gravidity of the case women of the UR group was $2.95 \pm 1.41$, significantly higher than that of the non-UR group $(1.85 \pm 1.09)$. The proportion of primiparity in non-UR group $(72.7 \%)$ were significantly higher than UR group $(24.4 \%)$. There was a statistically significant difference in the gestational age at delivery ( $39.0 \pm 1.6 \mathrm{vs} .37 .04 \pm$ 3.52), birth weight ( $3296.9 \pm 470.1$ vs. $3016.59 \pm 755.1)$ and maternal hospital stay ( $4.3 \pm 4.1$ vs $7.7 \pm 5.3$ ) between the groups $(p<0.05)$. Compared to the non-UR group, the proportion of gestational hypertension (7.3\% vs. $1.1 \%)$, artificial reproductive technology (12.2\% vs. $4.0 \%)$, cesarean delivery ( $100 \%$ vs $39.9 \%)$, postpartum hemorrhage (31.7\% vs. $1.5 \%$ ), preterm birth (39.0\% vs. $6.6 \%$ ), and 5 -minute Apgar score $<7$ $(19.5 \%$ vs. $1.0 \%)$ were significantly higher in the UR group $(p<0.05)$. 
Table 1

Characteristics of mothers and newborns in study.

\begin{tabular}{|llll|}
\hline & Non-UR & UR & p value \\
\hline Mothers & & & \\
\hline Age (years) & $30.9 \pm 4.0$ & $35 \pm 3.78$ & $<0.001^{*}$ \\
\hline$>35$ y & $39313[18.8]$ & $24[58.5]$ & $<0.001^{*}$ \\
\hline Gravidity & $1.85 \pm 1.09$ & $2.95 \pm 1.413$ & $<0.001^{*}$ \\
\hline Primiparity & $152024[72.7]$ & $10[24.4]$ & $<0.001^{*}$ \\
\hline Gestational diabetes mellitus & $22793[10.9]$ & $6[14.6]$ & 0.605 \\
\hline Gestational hypertension & $2300[1.1]$ & $3[7.3]$ & $0.002^{*}$ \\
\hline Artificial reproductive technology & $8365[4.0]$ & $5[12.2]$ & $0.023^{*}$ \\
\hline Hospital stay & $4.30 \pm 4.10$ & $7.71 \pm 5.28$ & $<0.001^{*}$ \\
\hline Postpartum hemorrhage & $3137[1.5]$ & $13[31.7]$ & $<0.001^{*}$ \\
\hline Deliveries/Newborns & & & $<0.001^{*}$ \\
\hline Cesarean delivery & $83436[39.9]$ & $41[100]$ & $<0.001^{*}$ \\
\hline Gestational age (weeks) & $39.00 \pm 1.60$ & $37.04 \pm 3.52$ & $0.001^{*}$ \\
\hline Preterm birth (<37 weeks) & $13801[6.6]$ & $16[39.0]$ & $<0.001^{*}$ \\
\hline Birth weight (g) & $3296.9 \pm 470.1$ & $3016.59 \pm 755.1$ & $0.022^{*}$ \\
\hline Macrosomia & $11083[5.3]$ & $1[2.4]$ & 0.639 \\
\hline 5 min Apgar < 7 & $2091[1.0]$ & $8[19.5]$ & $<0$ \\
\hline Values are expressed as mean \pm standard deviation or number. & & \\
\hline UR, Uterine rupture & & & \\
\hline
\end{tabular}

Table 2 displayed the occurrence of obstetrical risk factors in complicated and not complicated UR groups. Among all patients with UR, $16(39.0 \%)$ had maternal and fetal complications. Compared with not complicated UR, women in complicated UR group had higher proportions of primiparity, uterine myomectomy history, artificial reproductive technology use, blood transfusion, intensive care unit (ICU) admission, and complete UR. Complicated UR group also presented a larger amount of bleeding, a longer 
hospital stay, a higher probability of preterm birth, multiple pregnancy, a smaller rupture gestational weeks, a lower birth weight and prevalence of previous cesarean history. 
Table 2

Characteristics of mothers and newborns in complicated and not complicated uterine rupture

Complicated

16

Mothers

Age (years)

$>35 y$

Gravidity

Primiparity

Intrauterine operation

Gestational diabetes mellitus

Gestational hypertension

Artificial reproductive technology

Scarred uterus

Previous cesarean

Previous UM

Previous cornual pregnancy

TOLAC

Rupture of GA

Interval since last operation

Diagnosed in surgery

Blood loss

Transfusion

Intensive care unit

Hospital stay
$35.77 \pm 4.38$

$10[62.5]$

$3(1.5-4)$

$8[50]$

$10[62.5]$

$2[12.5]$

$3[18.75]$

$4[25]$

$13[81.25]$

$6[37.5]$

$5[31.25]$

$3[18.75]$

2[12.5]

$36.14(30.86-37.86)$

$4(2.5-6.5)$

10[62.5]

1250(1100-2675)

$8[50]$

$11[68.75]$

7(5-10.5)
Not complicated

25

I

$\mathbf{P}$

$34.56 \pm 3.64$

0.357

$14[56]$

0.680

$3(2-3.5)$

0.517

2[8]

$0.002^{\star}$

12[48]

0.364

4[16]

0.757

$0[0]$

0.053

1[4]

$0.045^{\star}$

$25[100]$

0.053

22[88]

$0.001^{\star}$

$1[4]$

$0.016^{*}$

[8]

0.305

8[32]

0.156

38.71(37.43-39.79)

$0.001^{\star}$

4(3-6.5)

0.584

$10[40]$

0.16

$300(300-400)$ $<0.001^{\star}$

$1[4]$

$0.001^{*}$

$1[4]$

$<0.001^{\star}$

$5(4-7)$

$0.043^{*}$

Values are expressed as mean \pm standard deviation, number, or median (Q1-Q3).

TOLAC, trial of labour after caesarean delivery; GA, gestational age; NICU, neonatal intensive care unit; UM, uterine myomectomy; 


\begin{tabular}{|llll|}
\hline & Complicated & Not complicated & P \\
\hline Abnormal fetal heart rate & $11[68.75]$ & $6[24]$ & $0.005^{*}$ \\
\hline Vaginal bleeding & $7[43.75]$ & $6[24]$ & $0.007^{*}$ \\
\hline Abdominal pain & $11[68.75]$ & $12[48]$ & 0.192 \\
\hline Other symptoms & $0[0]$ & $5[20]$ & 0.137 \\
\hline Emergency indication & $13[81.25]$ & $14[56]$ & 0.096 \\
\hline Complete UR & $9[56.25]$ & $6[24]$ & $0.036^{*}$ \\
\hline Deliveries/Newborns & & & $0.014^{*}$ \\
\hline Preterm birth (<37 weeks) & $10[62.5]$ & $6[24]$ & $0.018^{*}$ \\
\hline Twins & $4[25]$ & $0[0]$ & $0.040^{*}$ \\
\hline Birth weight (g) & $2970(1740-3500)$ & $3200(2945-3635)$ & \\
\hline Values are expressed as mean \pm standard deviation, number, or median (Q1-Q3). & \\
\hline $\begin{array}{l}\text { TOLAC, trial of labour after caesarean delivery; GA, gestational age; NICU, neonatal intensive care unit; } \\
\text { UM, uterine myomectomy; }\end{array}$ & & \\
\hline
\end{tabular}

Patients' rate with abnormal fetal heart rate ( $68.8 \%$ vs. $24.0 \%)$ and vaginal bleeding ( $43.8 \%$ vs. $24.0 \%)$ were significantly higher in the UR group with maternal and fetal complications. In complicated group, the range of ruptured gestational week was 23 to 40 weeks. In not complicated group, the earliest and the latest ruptured gestational week were 35 weeks and 40 weeks. No maternal death was observed. The perinatal fatality attributable to UR was 7.3\%. 21 (51.2\%) mothers were diagnosed with UR preoperatively, $20(48.8 \%)$ were diagnosed intraoperatively. The diagnosed time and the proportion of TOLAC were similar in the 2 groups $(p=0.16 ; 0.156)$.

Multiple logistic regression analysis was employed to examine whether signs and symptoms were associated with the presence of UR with complication (Table 3). The model, which included all signs and symptoms as independent variables, showed that abnormal fetal heart rate emerged as a significant and independent factor associated with the complicated UR compared with other signs. (OR $=12.45 ; 95 \% \mathrm{Cl}$ : $1.16-133.54 ; p<0.05)$. Other clinical signs were not statistically different. 
Table 3

Signs and symptoms of rupture uterus presented in a multi-variable analysis

\begin{tabular}{|lllll|}
\hline & OR & $95 \% \mathrm{Cl}$ & & P \\
\hline Abnormal fetal heart rate & 12.446 & 1.16 & 133.54 & $0.037^{\star}$ \\
\hline Vaginal bleeding & 0.807 & 0.055 & 11.932 & 0.876 \\
\hline Abdominal pain & 2.062 & 0.356 & 2.062 & 0.419 \\
\hline Other symptoms & 0 & 0 & $/$ & 0.999 \\
\hline
\end{tabular}

Figure 2 shows the rupture sites involved. 24 (59\%) cases were anterior lower uterine segment; $3(7 \%)$ cases had posterior segment rupture; $9(22 \%)$ cases were ruptured at the lateral segment; and $4(10 \%)$ cases were fundal segment rupture and one ruptured more than one place $(2 \%)$.

Detailed clinical information on all UR cases following laparoscopic myomectomy is shown in Table 4. 
Table 4

Detailed surgical findings and obstetric outcomes of the six cases with uterine rupture following laparoscopic myomectomy

\begin{tabular}{|lllllll|}
\hline Patient & $\mathbf{1}$ & $\mathbf{2}$ & $\mathbf{3}$ & $\mathbf{4}$ & $\mathbf{5}$ & $\mathbf{6}$ \\
\hline Age(yr) & 30 & 39 & 44 & 33 & 37 & 32 \\
\hline Year of surgery & 2014 & 2007 & 2013 & 2015 & 2018 & 2016 \\
\hline Number of myoma removed & 5 & 1 & 2 & 2 & 2 & 2 \\
\hline Myoma type & $\mathrm{IM}$ & $\mathrm{IM}$ & $\mathrm{IM}, \mathrm{SS}$ & $\mathrm{IM}$ & IM, SS & IM \\
\hline Myoma size(cm) & $6,3 \star 4$ & 6 & $5,1.5$ & $3 * 2$ & 6,1 & 6,2 \\
\hline Uterine incision & MP & MP & MP & MP & MP & MP \\
\hline Cavity entered & No & No & No & No & No & No \\
\hline Hemostasis type & BP,S & BP,S & BP,S & BP,S & BP,S & BP,S \\
\hline Stitches & 3 & 2 & 2 & 2 & 2 & 2 \\
\hline Anti-adhesion agents & Layers & Layers & Layers & Layers & Layers & Layers \\
\hline $\begin{array}{l}\text { Interval from surgery to } \\
\text { pregnancy(yr) }\end{array}$ & No & No & No & DM & DM & Yes \\
\hline Gestational week of rupture & 2 & 9 & 5 & 3 & 2 & 4 \\
\hline Labor & 31.43 & 36.43 & 37.43 & 30.29 & 23 & 35.43 \\
\hline $\begin{array}{l}\text { Volume of bleeding(ml) } \\
\text { Number of fetuses }\end{array}$ & No & No & No & No & No & No \\
\hline Fetal survival & 3250 & 800 & 2000 & 2500 & 2850 & 1250 \\
\hline Maternal survival & 1 & 1 & 1 & 1 & 1 & 1 \\
\hline $\begin{array}{l}\text { BP, bipolar electrosurgery; DM, data missing; IM, intramural; MP, monopolar electrosurgery; S, suture; } \\
\text { SS, subserosal; }\end{array}$ & No & Yes & Yes & No & No & Yes \\
\hline
\end{tabular}

\section{Discussion}

UR in pregnancy is rare, but when it occurs the consequences can be life-threatening to both mother and fetus $[13,14]$. The occurrence of UR varies in different parts of the world. Globally, the incidence of UR is $0.07 \%$ with the tendency of being lower in developed countries than developing countries[1] [15]. The rate of UR in our study was $0.0196 \%$, consistent with the rate of developed countries. There were no cases of maternal death due to UR in our study. 
There has been wide variation in the aetiology UR over years[16-18], where the increase rate of TOLAC and the use of uterotonics have created the two most common predisposing factors in the developed countries $[9,15,19,20]$. However, the major causes of UR in developing countries are both obstetric and non-obstetric multitude of factors: multi-gravidity, teen-age pregnancy, old primi, poor socio-economic status, previous cesarean section scar, unsupervised labor and unwise use of uterotonic agents[4].

Our study showed that the key risk factor of UR was the presence of scar, and previous cesarean section is the most important cause of uterine scarring. Therefore, to reduce UR rate, we need to strictly control the indication of cesarean section so as to reduce the rate of cesarean section. Globally, cesarean delivery rates have been steadily increasing over the past 20-30 years[21-23]. A major contributor to this has been elective repeat cesarean sections. Approximately one-third to half of elective cesareans are performed because of a history of cesarean delivery[21, 24, 25]. Routine elective repeat cesarean section for all women with a prior cesarean section is not universally advocated, desired, or without risk. Furthermore, multiple cesarean sections also carry the increased risk of placenta previa and placenta accrete with future pregnancies[26]. And such a policy would result in significant financial cost [27]. However, VBAC limited such problems. As another mode of birth after caesarean section, VBAC is associated with fewer complications, such as shorter maternal hospitalization, less blood loss, and a decreased incidence of puerperal infections and thrombotic events[28]. TOLAC is a safe option for most people and 75\% women may be successful[29]. Recent years, VBAC has been supported as a way to decrease related complications and slow the increase in cesarean births to some extents. In Norway, all mothers with one previous caesarean section are offered a chance of TOLAC unless there is an absolute contra-indication. The TOLAC rate is high with $51 \%$, and $80 \%$ succeed $^{[30]}$. VBAC is being advocated by more and more countries, but in China, the VBAC rate was only $9.6 \%$ in 2016 , as compared to $12.4 \%$ in the United States in the same year[31,32]. While TOLAC is accepted practice in hospitals with advanced medical equipment and obstetric skills, it is still controversial. A successful VBAC is associated with fewer complications compared with elective repeat cesarean delivery, whereas a failed TOLAC is associated with more complications[33]. We can see TOLAC has gone through three stages in US. Stage one, VBAC rates had increased from $5 \%$ in 1985 to $28.3 \%$ by 1996 as recommendations favored TOLAC; Stage two, the VBAC rate had decreased to $8.5 \%$ by 2006 as the number of UR and other complications related to TOLAC increased. Some hospitals stopped offering TOLAC altogether; Stage three, VBACs had been on the rise again since 2016 and increased to 13.3\% by 2018, when a balance between TOLAC and safety was reached ${ }^{[32,33]}$. U.S experience is worth learning and most part of China is going through the stage two, so we can see the reversal of the VBAC. Therefore, promoting TOLAC in China and ensuring the safety is needed. In our study, we were expecting UR rates to be higher as people attempted a TOLAC increased. However, this was not the case here and ruptures occurring after TOLAC were not more serious. Our hospital is one of the three hospitals with the largest number of births in China, and Shanghai is one of the most advanced medical treatment areas in China, which is close to developed countries, so we have rich medical experience to reduce the occurrence of UR and ensure the maternal and perinatal safety. Our study provides evidence that under the condition of strict control and indication, TOLAC is safe and reliable and worth carrying out. With the implementation of the policy of encouraging 
birth in China, more and more second-child pregnant women choose to attempt a TOLAC, the rate of cesarean section and consequent risk of UR will decline as a whole, and the national medical burden and financial expenditure can be reduced.

The other two causes of uterine scarring in our study are previous myomectomy and previous cornual pregnancy. All our cases with a previous myomectomy surgery were performed by laparoscopy. With the rise of minimally invasive techniques, laparoscopic surgeries are being performed in greater numbers today than ever before. Despite overwhelming evidence that laparoscopic myomectomy is minimally invasive and associated with fewer perioperative complications, there is one concern that is still under debate, i.e., does laparoscopic myomectomy increase risk of subsequent UR? Some previous studies showed there was no difference between laparoscopic and open myomectomy on the risk of UR while others demonstrated that laparoscopic procedure increased this risk compared to open approach because it was believed to result in incompletely repaired muscle defects ${ }^{[34-37]}$. The use of powered instruments, limited instrumentation use and impossibility of palpation might be the reasons. Some techniques including multi-layer closure of the myometrium and limited use of electrosurgical energy should be adhered to by surgeons to decrease the risk[37]. In our study, it seems to lead to more serious outcomes regarding the six UR cases following laparoscopic myomectomy. Among them four had excessive blood loss above $2000 \mathrm{ml}$ and presented signs of hemorrhagic shock, three had the worst outcome, i.e., the fetuses did not survive. They might even be influenced by long-term sequelae, which can adversely affect subsequent pregnancies. The removed myoma size and number in UR patients were within average range of normal cases of laparoscopic myomectomy, which is consistent with other studies[37, 38].And there is no evidence indicating the best contraception period prior to pregnancy after myomectomy to avoid UR. Currently this interval varies by facility ${ }^{[34]}$.Some suggested 12 months might be adequate while others concluded there was no safe interval ${ }^{[34,38,39]}$. In our study, the only UR case without serious complication after laparoscopic myomectomy had an interval for nine years, which is the longest. Thus, it seems to keep the duration of the contraception period longer will be safer for patients with a history of laparoscopic myomectomy. Therefore, clinicians must remain vigilant, particularly in patients with a history of laparoscopic myomectomy. And whatever the cause of scar uterus, special monitoring is needed during pregnancy and childbirth to ensure the health of the mother and newborn.

In contrast to UR in women attempting TOLAC, the UR in women with unscarred uteruses occurs often completely unexpectedly. We found an incidence of UR among women with no previous uterine scar was $3 / 209112$ deliveries, which was in agreement of the incidence found by Thisted et al based on data from the Danish Medical Birth Registry[20]. All three UR cases in our study were uncompleted UR found during the cesarean section with almost the same maternal and fetal complications rates as scarred uterus. Among them, two (2/3) were multiple pregnancy with uterus contraction before the cesarean section, one fell to birth vaginally because of obstructed labour. Our findings suggest that multiple pregnancy and obstructed labour are two major risk factors for UR in patients without a history of previous uterus surgery, which is in line with the recent reports published by Gibbins et al, Vandenberghe et al and Vilchez et al [40-42]. 
Timely detection of UR is conducive to improving maternal and infant outcomes. Symptoms are the only indicators that change dynamically, which can provide first-hand information for the doctors. In the past, caregivers were taught to look for classic signs such as sudden tearing uterine pain, vaginal hemorrhage, cessation of uterine contractions, Bandl's ring and regression of the fetus[43,44]. However, some studies have shown that these signs are not specific and often absent $[43,45]$. Our study shows that the change of the fetal heart rate is the most reliable presenting clinical symptom. Most of the cases also presented with abnormal pain and vaginal bleeding. Alertness to these signs is the key to the timely rescue and successful management. Other studies have the same conclusions consistent with ours[43, 45].

The most common site of rupture was in the lower uterine segment $(58.5 \%)$ in our study, which was the scar site of the previous cesarean section. This result is consistent with the findings of the study done by Rizwan et al[4], in which $80 \%$ of the rupture was observed in the lower uterine segment.

Our study has several strengths: (1)a population-based single-centered study, (2) covering a large period between 2013 and 2020, (3) Because all patients delivered in a medical institution, we have a complete and systematic review of all medical records. All patients were followed up six weeks after delivery and no serious complications were found after discharge. Also, the study is limited to Shanghai subjects and has limitations owing to the retrospective design. It only represents the level of developed regions in China. The situation in other parts of china is still unknown, so further research is needed to understand the generalizability of the study findings.

In conclusion, UR is a disastrous and fatal event for obstetricians and patients. In order to reduce maternal and infant mortality, obstetricians should give enough attention to the pregnant women with high risk factors by strengthening the monitoring. TOLAC is a safe and worth promoting type of delivery for the patients, and still has a long way to go in Shanghai and China.

\section{Abbreviations}

$\mathrm{Cl}$, confidence intervals

ICU, intensive-care unit

NICU, neonatal intensive-care unit

OR, Odds ratios

TOLAC, trial of labour after cesarean delivery

UR, uterine rupture

VBAC, vaginal birth after a caesarean section

\section{Declarations}




\section{Ethics approval and consent to participate}

This study was approved by the Ethics Review Committee of Shanghai First Maternity and Infant Hospital, Tongji University School of Medicine (reference number: KS20268). We declare that all methods of this study were performed in accordance with the relevant guidelines and regulations (Declaration of Helsinki). Permission to access charts of mothers for retrieving data obtained from Shanghai First Maternity and Infant Hospital. Because the study was a retrospective chart review, the Ethics Review Committee of Shanghai First Maternity and Infant Hospital, Tongji University School of Medicine has waived the requirement of the informed consent for this study. However, confidentiality was maintained when handling each case files.

\section{Consent for publication}

Not required.

\section{Availability of data and materials}

Data are available upon reasonable request. Prospective scientists who are interested in are welcomed to contact the corresponding author via e-mail.

\section{Competing interests}

The authors declare that they have no competing interests.

\section{Funding}

This research was supported by National Natural Science Foundation of China(81873816; 82071629);Pudong Commission of Health and Family Planning(PW2019D-13)

\section{Authors' contributions}

SW and MY participated in interpretation of data and involved in drafting the manuscript. JP, XZ, YW and QS analyzed the data and critically revised the manuscript. CZ, GW and XH made substantial contributions to conception and design, interpreted the data, and critically revised the manuscript. All authors read and approved the final manuscript.

\section{Acknowledgement}

We thank the study participants for permitting us to use their personal data.

\section{References}

1. Hofmeyr GJ, Say L, Gulmezoglu AM: WHO systematic review of maternal mortality and morbidity: the prevalence of uterine rupture. BJOG : an international journal of obstetrics and gynaecology 
2005, 112(9):1221-1228.

2. Fox NS, Gerber RS, Mourad M, Saltzman DH, Klauser CK, Gupta S, Rebarber A: Pregnancy outcomes in patients with prior uterine rupture or dehiscence. Obstetrics and gynecology 2014, 123(4):785-789.

3. Ronel D, Wiznitzer A, Sergienko R, Zlotnik A, Sheiner E: Trends, risk factors and pregnancy outcome in women with uterine rupture. Archives of gynecology and obstetrics 2012, 285(2):317-321.

4. Rizwan N, Abbasi RM, Uddin SF: Uterine rupture, frequency of cases and fetomaternal outcome. JPMA The Journal of the Pakistan Medical Association 2011, 61(4):322-324.

5. Chauhan SP, Martin JN, Jr., Henrichs CE, Morrison JC, Magann EF: Maternal and perinatal complications with uterine rupture in 142,075 patients who attempted vaginal birth after cesarean delivery: A review of the literature. American journal of obstetrics and gynecology 2003, 189(2):408417.

6. Vilchez G, Hoyos LR, Maldonado MC, Lagos M, Kruger M, Bahado-Singh R: Risk of neonatal mortality according to gestational age after elective repeat cesarean delivery. Archives of gynecology and obstetrics 2016, 294(1):77-81.

7. Berhe Y, Wall LL: Uterine rupture in resource-poor countries. Obstetrical \& gynecological survey 2014, 69(11):695-707.

8. Motomura K, Ganchimeg T, Nagata C, Ota E, Vogel JP, Betran AP, Torloni MR, Jayaratne K, Jwa SC, Mittal S et al: Incidence and outcomes of uterine rupture among women with prior caesarean section: WHO Multicountry Survey on Maternal and Newborn Health. Scientific reports 2017, 7:44093.

9. Al-Zirqi I, Daltveit AK, Forsén L, Stray-Pedersen B, Vangen S: Risk factors for complete uterine rupture. American journal of obstetrics and gynecology 2017, 216(2):165.e161-165.e168.

10. Markou GA, Muray JM, Poncelet C: Risk factors and symptoms associated with maternal and neonatal complications in women with uterine rupture. A 16 years multicentric experience. European journal of obstetrics, gynecology, and reproductive biology 2017, 217:126-130.

11. Lannon SMR, Guthrie KA, Vanderhoeven JP, Gammill HS: Uterine rupture risk after periviable cesarean delivery. Obstetrics and gynecology 2015, 125(5):1095-1100.

12. Al-Zirqi I, Stray-Pedersen B, Forsen L, Daltveit AK, Vangen S: Uterine rupture: trends over 40 years. BJOG : an international journal of obstetrics and gynaecology 2016, 123(5):780-787.

13. Vernekar M, Rajib R: Unscarred Uterine Rupture: A Retrospective Analysis. Journal of obstetrics and gynaecology of India 2016, 66(Suppl 1):51-54.

14. Khanam RA, Khatun M: Ruptured uterus: an ongoing tragedy of motherhood. Bangladesh Medical Research Council bulletin 2001, 27(2):43-47.

15. Guise JM, McDonagh MS, Osterweil P, Nygren P, Chan BK, Helfand M: Systematic review of the incidence and consequences of uterine rupture in women with previous caesarean section. BMJ (Clinical research ed) 2004, 329(7456):19-25.

16. Astatikie G, Limenih MA, Kebede M: Maternal and fetal outcomes of uterine rupture and factors associated with maternal death secondary to uterine rupture. BMC pregnancy and childbirth 2017, 
17(1):117.

17. Sahin HG, Kolusari A, Yildizhan R, Kurdoglu M, Adali E, Kamaci M: Uterine rupture: a twelve-year clinical analysis. The journal of maternal-fetal \& neonatal medicine : the official journal of the European Association of Perinatal Medicine, the Federation of Asia and Oceania Perinatal Societies, the International Society of Perinatal Obstet 2008, 21(7):503-506.

18. Rouzi AA, Hawaswi AA, Aboalazm M, Hassanain F, Sindi O: Uterine rupture incidence, risk factors, and outcome. Saudi medical journal 2003, 24(1):37-39.

19. Smith GC, White IR, Pell JP, Dobbie R: Predicting cesarean section and uterine rupture among women attempting vaginal birth after prior cesarean section. PLoS medicine 2005, 2(9):e252.

20. Thisted DL, Mortensen LH, Krebs L: Uterine rupture without previous caesarean delivery: a population-based cohort study. European journal of obstetrics, gynecology, and reproductive biology 2015, 195:151-155.

21. Barber EL, Lundsberg LS, Belanger K, Pettker CM, Funai EF, Illuzzi JL: Indications contributing to the increasing cesarean delivery rate. Obstetrics and gynecology 2011, 118(1):29-38.

22. Denham SH, Humphrey $T$, deLabrusse $C$, Dougall $N$ : Mode of birth after caesarean section: individual prediction scores using Scottish population data. BMC pregnancy and childbirth 2019, 19(1):84.

23. Betrán AP, Ye J, Moller AB, Zhang J, Gülmezoglu AM, Torloni MR: The Increasing Trend in Caesarean Section Rates: Global, Regional and National Estimates: 1990-2014. PloS one 2016, 11(2):e0148343.

24. Wingert A, Johnson C, Featherstone R, Sebastianski M, Hartling L, Douglas Wilson R: Adjunct clinical interventions that influence vaginal birth after cesarean rates: systematic review. $B M C$ pregnancy and childbirth 2018, 18(1):452.

25. Dunsmoor-Su R, Sammel M, Stevens E, Peipert JL, Macones G: Impact of sociodemographic and hospital factors on attempts at vaginal birth after cesarean delivery. Obstetrics and gynecology 2003, 102(6):1358-1365.

26. Mankuta DD, Leshno MM, Menasche MM, Brezis MM: Vaginal birth after cesarean section: trial of labor or repeat cesarean section? A decision analysis. American journal of obstetrics and gynecology 2003, 189(3):714-719.

27. Grobman WA, Peaceman AM, Socol ML: Cost-effectiveness of elective cesarean delivery after one prior low transverse cesarean. Obstetrics and gynecology 2000, 95(5):745-751.

28. McMahon MJ, Luther ER, Bowes WA, Jr., Olshan AF: Comparison of a trial of labor with an elective second cesarean section. The New England journal of medicine 1996, 335(10):689-695.

29. Knight HE, Gurol-Urganci I, van der Meulen JH, Mahmood TA, Richmond DH, Dougall A, Cromwell DA: Vaginal birth after caesarean section: a cohort study investigating factors associated with its uptake and success. BJOG : an international journal of obstetrics and gynaecology 2014, 121(2):183-192.

30. Al-Zirqi I, Stray-Pedersen B, Forsén L, Vangen S: Uterine rupture after previous caesarean section. BJOG : an international journal of obstetrics and gynaecology 2010, 117(7):809-820. 
31. Mu Y, Li X, Zhu J, Liu Z, Li M, Deng K, Deng C, Li Q, Kang L, Wang Y et al: Prior caesarean section and likelihood of vaginal birth, 2012-2016, China. Bulletin of the World Health Organization 2018, 96(8):548-557.

32. Martin JA, Hamilton BE, Osterman MJK: Births in the United States, 2018. NCHS data brief 2019(346):1-8.

33. ACOG Practice Bulletin No. 205: Vaginal Birth After Cesarean Delivery. Obstetrics and gynecology 2019, 133(2):e110-e127.

34. Osada H: Uterine adenomyosis and adenomyoma: the surgical approach. Fertility and sterility 2018 , 109(3):406-417.

35. Gil Y, Badeghiesh A, Suarthana E, Mansour F, Capmas P, Volodarsky-Perel A, Tulandi T: Risk of uterine rupture after myomectomy by laparoscopy or laparotomy. Journal of gynecology obstetrics and human reproduction 2020, 49(8):101843.

36. Cobellis L, Pecori E, Cobellis G: Comparison of intramural myomectomy scar after laparotomy or laparoscopy. International journal of gynaecology and obstetrics: the official organ of the International Federation of Gynaecology and Obstetrics 2004, 84(1):87-88.

37. Parker WH, Einarsson J, Istre O, Dubuisson JB: Risk factors for uterine rupture after laparoscopic myomectomy. Journal of minimally invasive gynecology 2010, 17(5):551-554.

38. Koo YJ, Lee JK, Lee YK, Kwak DW, Lee IH, Lim KT, Lee KH, Kim TJ: Pregnancy Outcomes and Risk Factors for Uterine Rupture After Laparoscopic Myomectomy: A Single-Center Experience and Literature Review. Journal of minimally invasive gynecology 2015, 22(6):1022-1028.

39. Milazzo GN, Catalano A, Badia V, Mallozzi M, Caserta D: Myoma and myomectomy: Poor evidence concern in pregnancy. The journal of obstetrics and gynaecology research 2017, 43(12):1789-1804.

40. Gibbins KJ, Weber T, Holmgren CM, Porter TF, Varner MW, Manuck TA: Maternal and fetal morbidity associated with uterine rupture of the unscarred uterus. American journal of obstetrics and gynecology 2015, 213(3):382.e381-386.

41. Vandenberghe G, De Blaere M, Van Leeuw V, Roelens K, Englert Y, Hanssens M, Verstraelen H: Nationwide population-based cohort study of uterine rupture in Belgium: results from the Belgian Obstetric Surveillance System. BMJ open 2016, 6(5):e010415.

42. Vilchez G, Nazeer S, Kumar K, Warren M, Dai J, Sokol RJ: Contemporary epidemiology and novel predictors of uterine rupture: a nationwide population-based study. Archives of gynecology and obstetrics 2017, 296(5):869-875.

43. Leung AS, Leung EK, Paul RH: Uterine rupture after previous cesarean delivery: maternal and fetal consequences. American journal of obstetrics and gynecology 1993, 169(4):945-950.

44. Phelan JP: Uterine rupture. Clinical obstetrics and gynecology 1990, 33(3):432-437.

45. Cowan RK, Kinch RA, Ellis B, Anderson R: Trial of labor following cesarean delivery. Obstetrics and gynecology 1994, 83(6):933-936. 
100000

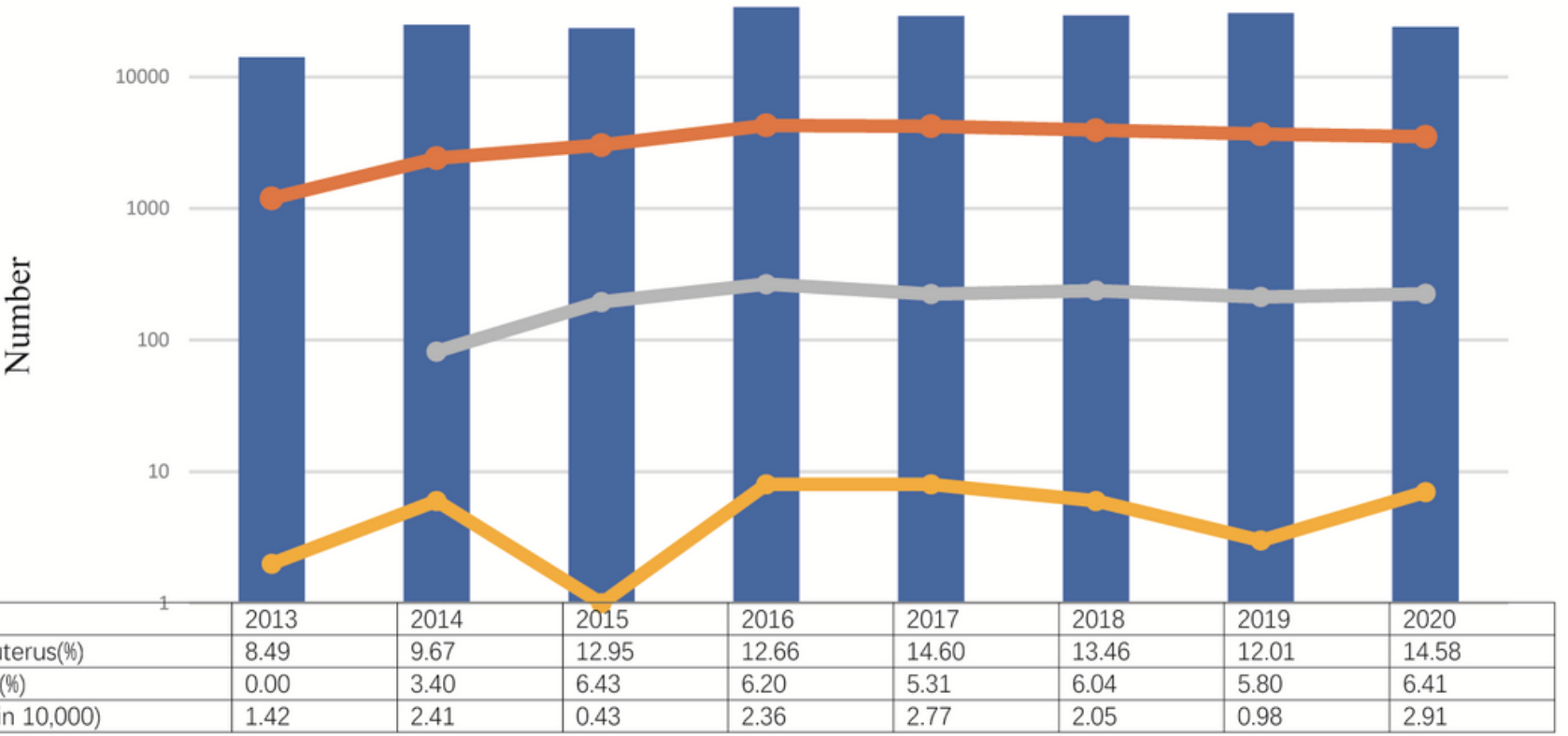

\section{Figure 1}

Trend of uterine rupture, scar uterus and VBAC at Shanghai First Maternity and Infant Hospital, 20132020

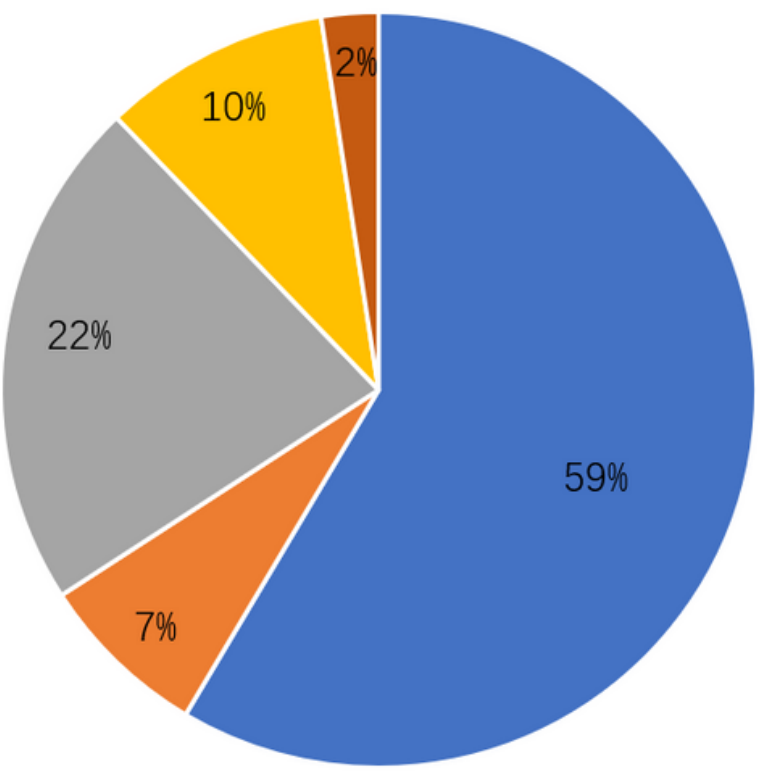

- Anterior lower segment = Posterior = Lateral = Fundal = More than one place 
Figure 2

Site of uterine rupture

Page 19/19 